\title{
A injunção da participação no campo ambiental ou a questão da incorporação dos "públicos" nos espaços de discussão
}

\section{Resumo}

Quer se fale de "virada" ou de "imperativo" deliberativo, a democracia participativa está no bojo do tratamento dos problemas de meio ambiente, envolvendo o público. Dois problemas são abordados neste artigo: de um lado, a forma particular assumida por essa incorporação de diferentes públicos no que se denomina "democracia técnica"; de outro, os problemas, frequentemente subestimados pelas abordagens críticas da participação, de articulação entre os espaços de discussão gerados pelas questões ambientais e os tópicos tradicionais da vida social regulados pela democracia representativa. Esta análise se baseia em um estudo de caso extraído da aplicação das políticas agroambientais em uma zona úmida, na França, onde a gestão da água é estratégica. As dificuldades encontradas pelos vereadores para ocupar um lugar legítimo no exercício democrático centrado na participação dos diferentes públicos dão margem a uma reflexão sobre a necessidade de repensar a legitimidade da democracia representativa na gestão de problemas que, como aqueles ligados ao meio ambiente, levantam a questão das relações entre ciências e sociedades.

Palavras-chave: Participação. Representação. Democracia técnica. Legitimidade. Ruralidade.

${ }^{*}$ CNRS - LADYSS - Paris Ouest Nanterre La Défense. 


\section{The imperative of participation in the environmental field or the issue of incorporating the "public" into spaces for debate $^{1}$}

\section{Abstract}

Whether we speak of deliberative "turn" or deliberative "imperative", participatory democracy is at the heart of addressing environmental problems, involving the public. Two issues are addressed here: first, the particular form of this incorporation of distinct audiences into what is referred to as a "technical democracy"; on the other hand, problems often underestimated by the critiques of participation referred to the connection between the discussions forums created by the environmental issues and the traditional issues of social life regulated by representative democracy. This analysis is based on a case study on the implementation of agri-environmental policies in France, particularly in a wet area where water management is strategic. The difficulties faced by local town councilors to hold a legitimate place within the democratic arena focused on the participation of various segments of the public is an opportunity to reflect on the need to rethink the legitimacy of representative democracy in the management of problems that, just as those related to the environment, raise the question of the relationship between sciences and societies.

Keywords : Participation. Representation. Technical democracy. Legitimacy. Rurality

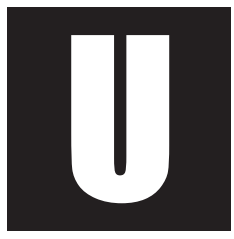

m dos aspectos mais surpreendentes das novas políticas de desenvolvimento é que, para sua aplicação, os atores sociais são obrigados a entrar em acordo. Essa obrigação está prevista em inúmeras políticas europeias a partir da década de 1990, particularmente naquelas aplicadas à agricultura nas políticas ditas "agroambientais" (regulamento 2078 sobre o ambiente agrícola, em 1992) ou ao espaço rural (diretriz Habitats, também em 1992). Como ilustração concreta tem-se o princípio de subsidia-

\footnotetext{
${ }^{1}$ Tradução de Patrícia C. R. Reuillard (UFRGS); Revisão técnica de J. Almeida (UFRGS).
} 
riedade (Millon-Delsol, 1993) ou, de modo mais geral, o surgimento de um novo modelo de "governança", que tende a associar, aos processos de decisão, diferentes participantes públicos ou privados, que se deparam com problemas cada vez mais complexos. Em todos os casos, é manifesto o desejo de envolver o pacto no processo decisório e, independentemente da posição dos atores nesse processo, a busca de um acordo ou de acordos ultrapassa uma necessidade procedimental.

Para caracterizar o sistema político na França ${ }^{2}$, os cientistas políticos (Crozier e Thoenig, 1976) falaram de regulação cruzada, associando três figuras: o Estado, o chefe de departamento 3 e o vereador. Designam, assim, a exitosa modernização do pós-guerra, ou seja, uma programação centralizada e planejada (o ordenamento do território) para a qual o Estado contribui com sua competência técnica (as grandes corporações de Estado $\left.^{4}\right)$, articulando sua implantação por meio de acordos entre a administração territorial (o engenheiro qualificado de prefeito técnico ${ }^{5}$ ) e

\footnotetext{
${ }^{2}$ Administrativamente, a França é dividida em circunscrições territoriais, de três níveis: municípios (36.570), departamentos (96) e regiões (22) (N. de trad.).

${ }^{3} \mathrm{~A}$ função de chefe de departamento (préfet, em francês) foi criada por Napoleão Bonaparte, então primeiro cônsul, em 17 de fevereiro de 1800, pela lei de 28 pluvioso do ano VIII do calendário republicano. É um alto funcionário que geralmente exerce funções importantes nas administrações do Estado em escala territorial. Na França, este termo designa a função de chefe de departamento ou chefe de região e também o grau de seu titular, membro da associação de chefes de departamento. Alguns membros dessa associação, que conta aproximadamente com 250 chefes, não exercem uma função territorial.

${ }^{4} \mathrm{Na}$ França, algumas das grandes corporações do Estado fornecem "altos funcionários" da função pública, geralmente recrutados na Escola Nacional da Administração (ENA), na Escola Politécnica e nas Escolas Normais Superiores, que assumem postos nos escalóes superiores da administração. Ao lado das grandes corporações administrativas (Conselho de Estado, Tribunal de Contas, etc.), existem também as grandes corporações técnicas, como a dos Engenheiros de Pontes, Águas e Florestas, resultado da fusão, em 2009, da corporação dos Engenheiros, Pontes e Vias, criada em 1704, e da Engenharia Rural, das Águas e das Florestas. Essas corporações são uma exceção francesa e é a elas a que o texto se refere.

${ }^{5}$ A expressão prefeito técnico é de J.-C. Thoenig (1987, que designa assim a importância da grande corporação técnica na gestão territorial, que preenche uma missão de interesse gral do mesmo modo que o chefe administrativo, representante do Estado nos níveis departamental e regional.
} 
os vereadores. O dispositivo francês de cogestão agrícola que organizou a modernização da agricultura é o protótipo por excelência desse modelo (Coulomb e Nallet, 1972; Billaud, 1990). A partir dos anos 1990, os cientistas políticos se referem mais ao modelo de territorialização da ação pública, no qual o território, mais do que o aparelho de Estado, constitui agora o lugar de definição dos problemas públicos (Duran e Thoenig, 1996).

Falando hoje em dia de territorialização da ação pública, os cientistas políticos salientam a superação do modelo de regulação cruzada em proveito daquele de institucionalização da ação coletiva, no qual a definição dos problemas e dos modos de regulação fica a cargo de atores locais múltiplos dos territórios, para gerenciar os problemas mais de perto. $\mathrm{O}$ Estado enquadra a ação (em termos de procedimentos e objetivos), mas parece ater-se a um papel de engenharia institucional, propondo, entre outras, a injunção do "participativo" entre as partes envolvidas. A definição do problema passa a ser a questão central e parece relegar ao segundo plano a questão tradicional (para o vereador) da captação de recursos. No modelo tradicional, a articulação entre uma questão setorial e uma visão de mundo (um referencial global, como, por exemplo, a autonomia alimentar na agricultura) era garantida pelo lugar ocupado pelo Estado (avalista do interesse geral). Atualmente, essa articulação parece incumbir ao processo de ação coletiva, com a indeterminação que isso supõe, visto que essa ação não é dada, mas precisa ser construída.

Neste artigo, trataremos dos desafios representados pela associação entre essas diversas formas de democracia - tradicional (democracia representativa) e mais recente (democracia participativa) -, ambas sendo testadas pelo que alguns autores designam de democracia técnica (Callon et al. 2001), ou seja, aquela que se expressa em fóruns híbridos, arena de controvérsias entre questões científicas e industriais em torno de um objeto técnico. Na democracia técnica, a objetivação de situações com- 
plexas demanda equipamentos cognitivos - instrumentos, indicadores, modelos, etc. - que mobilizam as energias e levam a um enquadramento permanente por meio da padronização, o que se revela necessário quando não se quer ficar perdido na infinidade de causas apresentadas para explicar um fenômeno ou um problema. Os problemas ambientais se encaixam bem nessa configuração em que a ciência é requisitada para ordenar causalidades complexas demais, nas quais predomina a incerteza. Até mesmo os partidários de uma abordagem de evidence based policy (Laurent, 2011) reconhecem nas políticas ambientais uma complexidade específica, porque inflacionista, que também limita as capacidades da ciência para determinar sozinha a relação com os objetos (Sutherland et al., 2004). Para eles, as abordagens participativas teriam a virtude de limitar e relacionar as causas que caracterizam as questões ambientais.

$\mathrm{Na}$ tentativa de compreender o novo exercício democrático que acompanha a escalada dos problemas ambientais (e se inventa graças a ele), partiremos de um estudo de caso $^{6}$ que concerne ao que se chama de minipúblico, que prepara a implantação de um dispositivo agroambiental (Mormont, 1996), em uma área úmida ${ }^{7}$ situada no oeste da França. Antes de expor esse caso, que ilustra as tensões entre essas diferentes formas de democracia, mesmo que em pequena escala, contextualizaremos a problemática e as ambiguidades da injunção de uma democracia participativa; concluiremos nossa proposta com uma reflexão mais ampla sobre a refundação da ruralidade, acarretada por esse novo tipo de incorporação dos públicos no exercício democrático.

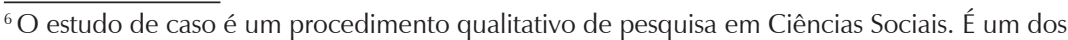
raros procedimentos da área que conjuga a observação direta (participante ou não) e diferentes fontes documentais relativas às práticas e discursos pertinentes ao objeto de estudo.

${ }^{7}$ Termos por vezes tratados de forma equivalente: várzea, pântano, brejo (N. de trad.).
} 


\section{A participação dos públicos na questão ambiental}

Afirmar que, ao estudar essa questão, se entra em bibliotecas separadas, como defende a introdução do primeiro número da revista Participations (Blondiaux e Fourniau, 2011) é pouco, pois há uma fragmentação das referências, dos conceitos e dos objetivos visados. É relacionada às questões de urbanismo e dos movimentos sociais que essa questão surge, desde a década de 1960, nas preocupações dos pesquisadores, mas a virada deliberativa (Sintomer, 2011) (participativa, para outros) se impõe na França a todas as áreas e objetos de pesquisa a partir dos anos 1990, após uma década de relativo desaparecimento e bem depois dos anglo-saxões.

Vaga também nos termos que designam as ações - pacto, negociação, democracia, cidadania, governança -, a participação se revela o denominador comum, a passagem obrigatória em qualquer situação. Quando se trata de abordar um problema público (nanotecnologia, transgênicos, etc.), surgem então comissões de cidadãos, conselhos de bairro, plenárias, etc. Mas, no caso das políticas públicas submetidas ao imperativo deliberativo (cf. a lei Barnier de 1995, por exemplo), encontram-se também comissões, comitês dedicados ao exercício de uma democracia participativa.

O mínimo que se pode dizer é que o entusiasmo e as dúvidas acerca dessa forma de exercício da democracia são compartilhados tanto pelos pesquisadores quanto pelos atores da sociedade civil. É evidente que todos compartilham o ideal de uma coprodução generalizada do que gera (ou pode gerar) o "bem comum", um ideal em que as assimetrias de poder e de informação se reduziriam para se chegar a um maior domínio coletivo dos problemas que nos escapam e que queremos controlar, isto é, torná-los suportáveis para nós. Mas também se faz uma leitura mais crítica dessa forma de democracia, menos ingênua segundo alguns, que consiste em nela ver, além de uma renovação da ação pública confrontada com problemas cada vez mais complexos (a territorialização), uma 
forma de construção da aceitabilidade social, senão um artifício dos poderes instituídos.

Embora os pesquisadores exercitem outras formas de seu ofício, envolvendo-se eles próprios em processos participativos - e não somente ocupando um lugar privilegiado para fazer observações -, eles também julgam que, na maioria das vezes, esses momentos de ação coletiva gerada pela participação - reivindicada ou procedimental - dos públicos têm uma autonomia bem relativa, visto que é no início do processo (no enquadramento, isto é, no momento em que se selecionam as questões e os problemas considerados legítimos) e no final (quando a decisão se concretiza) que o exercício de democracia conhece sua verdadeira hora da verdade. Todas essas reservas remetem ao temor de transformar a ação participativa em algo rotineiro que, em uma busca de aceitabilidade social, pode se assemelhar a uma gestão mais ou menos corriqueira dos conflitos e a um projeto de pacificação contínua. A democracia participativa provoca também perplexidade acerca das verdadeiras relações de força e de poder, que permanecem determinantes no momento da decisão e confirmam, quase sempre, as posições estabelecidas.

No entanto, segundo o historiador Pierre Rosanvallon (2011), essa ideia de participação tem raízes na Revolução Francesa. A ideia de participação é inseparável da ideia de comunidade, ela própria relacionada à de "sociedade dos iguais". O que faz o cidadão não é o fato de ser eleitor ( $1 \%$ dos cidadãos o eram no momento da Revolução), mas de pertencer a uma comunidade, de participar dela. A cidadania se construiu contra a impaciência das desigualdades, como dizem os historiadores, e remete, portanto, à participação coletiva em uma comunidade de habitantes. Desse ponto de vista, é grande a distância da problemática atual dos direitos e dos deveres ligados ao exercício da cidadania, em cuja origem há a reivindicação de ser "um dentre outros". 
Ser um dentre outros nas situações de democracia participativa é, evidentemente, uma utopia que pode prejudicar a democracia, se não se analisarem todas as contradições que permeiam as situações em que a participação do cidadão é o centro do processo político e supostamente um modo de governar. Diante dos desafios e dos problemas que um processo participativo pretende abranger, os atores não são iguais em termos de recursos sociais (os custos de participação não são os mesmos conforme as situações profissionais), de competências (por exemplo, a maior ou menor facilidade para falar em público), de posições sociais (em particular, o lugar na hierarquia social, etc.).

Porém, além da questão da igualdade, há um problema ainda mais específico quando a democracia participativa é central no tratamento das questões de meio ambiente e diz respeito a um processo de democracia técnica. Os historiadores das ciências e das técnicas nos lembram, de fato, que o surgimento da ciência moderna, a partir dos séculos XVII e XVIII, acompanhou ou ao menos coincidiu com o aparecimento de regimes representativos que colocaram a questão democrática em termos radicalmente novos. Essa ciência nova se estabeleceu, por assim dizer, à parte do debate público, em nome de sua capacidade de estabelecer a "verdade" e pautar os caminhos de um progresso contínuo. Essa separação entre a ordem democrática e a ordem dos conhecimentos científicos está em vias de abolição, ou, pelo menos, vem sofrendo inúmeras críticas nos últimos 40 anos. As crises sucessivas, sobretudo ambientais, questionaram essa pretensão das ciências de se desvincular do político, enquanto a sociologia das ciências (Latour e Woolgar, 1996) mostrava como seus recortes, escolhas epistêmicas ou metodológicas e modos de financiamento também constituem maneiras de estar no mundo que tangem ao político. Considerando que todo saber tem limites e uma parcialidade insuperável (Pestre, 2011), hoje se admite que as ciências não podem constituir uma verdade "absoluta". 
A virada participativa se inscreve de maneira explícita nesse contexto de reordenamento entre a ordem das ciências e a ordem democrática. Ela se situa mais particularmente neste exercício democrático que coloca em discussão nossas relações multiformes com os objetos que nos cercam e com os quais compomos incessantemente para "fazer sociedade". Essa discussão levanta a questão da participação do público na definição e na resolução das questões técnicas e científicas e, portanto, da relação desse público com as formas do conhecimento, certamente científicas, mas também "leigas" (Dewey, 2010). Disso se deduziram tipologias dos modos de articulação entre ciências e sociedades, como aquela proposta por um sociólogo (Callon, 1998), que distingue três modelos: o modelo da instrução pública (uma divisão entre cientistas e cidadãos bem informados pelos primeiros), o do debate público (em torno de especialistas que traçam as fronteiras das certezas e incertezas em matéria de ciência e de tecnologia, fronteiras que devem ser debatidas coletivamente) e, por fim, o modelo da coprodução dos saberes (no qual se opera uma descentralização em direção aos "não especialistas", que teriam competências cognitivas e sociais suscetíveis de uma produção de conhecimentos coletivos, que correlaciona cientistas e leigos). Evoca-se frequentemente esse último modelo como um objetivo a ser alcançado na recomposição das relações entre ciências e sociedades; contudo, embora existam casos confirmados de experimentação bem-sucedida desse modelo, como no envolvimento dos pacientes de AIDS nos protocolos de pesquisa médica (Dodier, 2003), isso permanece excepcional em relação aos dois outros.

Porém, acima de tudo e seguindo a Teoria do agir comunicacional de Habermas (1987), deduziu-se da necessidade de instaurar espaços dialógicos onde o que estava em questão no plano democrático era mais o foco na questão dos procedimentos (organizando os debates com todos os públicos envolvidos, velando pela representatividade, pelo acesso à 
palavra, etc.) do que resolver a questão da relação dos conhecimentos especializados, que fazem pouco caso, de fato, dos produtores de conhecimentos que compõem um coletivo. Em resumo, fez-se do ato participativo o princípio e o fim do exercício democrático confrontado com as ciências e as técnicas. Não se trata aqui de afirmar que os procedimentos de enquadramento e de organização das instâncias de debate se afastam da verdadeira questão democrática, que consiste em interrogar e de certo modo decifrar a relação com as técnicas que estruturam nossas atividades e nossas práticas sociais - e o caso de estudo proposto é uma ilustração clara das capacidades de reflexividade de atores "comuns". Mas pode-se questionar se, limitando-se a essa questão dialógica e procedural, não se reduz a capacidade dos atores participantes para fazer ou desfazer mundos (Pestre, 2011), pois esses mundos não estão incluídos nas situações de interação oferecidas pelo método participativo e dizem respeito também a configurações socioterritoriais (com suas pesadas heranças socioculturais) e a sequências de ação que ultrapassam amplamente o confronto produzido pela participação (Walzer, 1983).

Os debates em torno da democracia participativa tratam, portanto, de sua capacidade de representar um verdadeiro instrumento de governo e, no que tange às questões ambientais nas quais ela é mais solicitada, de enfrentar as crises e os desafios criados pela experiência da finitude do mundo. Tanto pesquisadores quanto atores da sociedade civil têm consciência de que é preciso combater seus desvios (quando, por exemplo, ela acarreta a (re)legitimação dos poderes instituídos - uso que os representantes políticos geralmente fazem dela -, ou dos poderes emergentes - como às vezes acontece por parte do mundo associativo). Eles percebem também que um risco a espreita quando a tecnologização crescente das escolhas democráticas ("equipar" os coletivos democráticos significa dar lugar aos conhecimentos produzidos em situação de ação e, portanto, não se limitar 
ao mero inventário de todos os saberes) pode arruinar uma verdadeira democratização das escolhas técnicas. Nesse sentido, o exercício democrático não responde somente à exigência do procedural e do dialógico, nem que seja porque a democracia participativa assume múltiplas formas, em particular aquelas que se refiram a uma democracia técnica.

Porém, esses debates raramente incidem sobre o ponto que abordamos aqui, ou seja, as dificuldades, senão as contradições, encontradas pela democracia participativa na relação com o exercício democrático tradicional (herdado, na França, da Revolução), isto é, a democracia representativa. De fato, no método procedural central do processo democrático comunicacional e cuja referência maior é a participação do público, a legitimidade dos representantes eleitos é, sem dúvida, a mais submetida à reinterpretação, pois essas arenas participativas se organizam primeiramente em torno dos participantes (os stakeholders) e dos especialistas ou cientistas. Deve-se ver na democracia participativa uma superação (senão uma substituição) da democracia representativa, ou se deve considerar que, na construção de nossas escolhas democráticas que apelam para a participação, o lugar dos representantes eleitos, símbolos da democracia representativa, não é evidente e deve então ser repensado? Esse questionamento um tanto binário parte da constatação de que, nesta fase particular de reconstrução das legitimidades (o que é justo e pode fazer parte do "bem comum"), o vereador, figura emblemática da representação mais elementar da democracia moderna, fica um pouco fragilizado ou, em todo caso, se confronta como cada participante - e, em nossa opinião, mais ainda - a essa necessidade de reinventar, de redefinir as bases de sua presença nas arenas técnicas geradas pelas políticas da natureza.

Não trazemos uma resposta definitiva a isso, mas ilustraremos o interesse de tal questionamento por meio de um estudo de caso que mostra que a perda de importância política dos vereadores foi necessária para garantir a incorporação dos públicos envolvidos em um espaço de discussão. 


\section{Um estudo de caso: história de um dispositivo agroambiental em uma zona úmida na França}

No início da década de 1990, a Europa criou um novo instrumento de politica pública em agricultura, as medidas agroambientais (Billaud, 2002), que instauraram um regime de subsídios para estimular práticas de produção que respeitassem o meio ambiente e compensar perdas de renda ou custos extras resultantes da implantação dessas práticas. Mais concretamente, ofereciam-se subsídios em caso de diminuição da utilização de adubo ou de pesticidas, de redução dos custos do rebanho, de manutenção de terras abandonadas, etc. Tratou-se de uma verdadeira virada na concepção da política agrícola comum, que questionava o modelo herdado do pós-guerra, que privilegiava os ganhos de produtividade em nome da vocação produtiva da agricultura. A ruptura também se dava no procedimento, já que apelar para um pacto entre todos os atores da ruralidade (agricultores, mas também pescadores, caçadores, associações de proteção ao meio ambiente...) para a implantação em campo significava um distanciamento do sistema de cogestão, que transformava os agricultores em parceiros privilegiados do Estado na aplicação da política. Nesse sentido, a política agroambiental inaugurou a democracia participativa para a agricultura e até mesmo, devido à importância dos objetos envolvidos (recursos naturais...), de uma forma de democracia técnica.

O dispositivo observado se situa no oeste da França. O parque regional Marais Poitevin é uma zona úmida de 112 mil hectares, alimentada por três bacias hidrográficas de 635 mil hectares. Distribuído em quatro tipos de áreas úmidas (não inundável, inundável, intermediário, mangue), ele é o arquétipo de uma regulação organizada por sindicatos de proprietários que, a partir de compartimentos hidráulicos, administram os níveis de água de modo autônomo. Os problemas enfrentados por essa gestão (seca e inundações crescentes, salinização ou rebaixamento sazonal do lençol, de- 
gradação da qualidade da água, açodamento da foz, etc.) provocam, desde os anos 1960, uma crise recorrente nos modos de gestão, devido a uma intensificação dos cultivos de cereais, que supõe saneamento e drenagem, acarreta uma grande diminuição dos prados úmidos (cerca de $60 \%$ entre 1979 e 1994) e se choca com os interesses da caça, da pesca, do turismo e das exigências de proteção ao meio. Criar um novo sistema de obrigações entre os atores sociais da gestão hidráulica demanda uma real criação de regras e procedimentos, o que a política agroambiental fez, ao convidar para "rodadas" todos os atores sociais envolvidos no uso da zona úmida. Eles precisavam definir os beneficiários dos auxílios e as parcelas que seriam objeto de uma série de especificações (três tipos de contratos conforme a importância do esforço ambiental efetivamente feito).

Observamos duas rodadas de discussão com cinco anos de distância a fim de determinar as modalidades do exercício de democracia participativa e, eventualmente, sua evolução. Esses dois momentos de que trata esta análise correspondem a duas etapas da política pública: seu lançamento e sua renovação contratual. Concretamente, essas discussões não se estenderam por cinco anos. Nas duas situações, o mesmo método foi aplicado: observação não participante das reuniões (uma dezena em cada rodada), tomada de notas, análise das atas das reuniões, que sintetizam as intervenções e registram os participantes de cada reunião, bem como sua qualificação.

Graças a essa comparação, percebe-se que o que é discutido em um primeiro momento não o é mais cinco anos depois, e que isso coincide com uma composição bem diferente da rodada de discussões. Tal transformação na representatividade do dispositivo corresponde de fato ao esboço de outro modelo de gestão, que só pode resultar de uma aprendizagem coletiva entre a primeira e a segunda rodadas. A evolução recente na gestão das áreas úmidas revela assim, por meio das políticas agroam- 
bientais, a concorrência de duas formas de exercício de uma democracia suscetível de definir o "bem comum", conforme vamos mostrar. De um lado, arranjos feitos a partir do direito de propriedade agrícola e que privilegiam a lógica do pertencimento local e territorial dos indivíduos; do outro, arranjos construídos a partir de acertos entre diferentes usuários do espaço rural e que privilegiam um ajuste provisório em situações singulares e incertas. No primeiro caso, os vereadores encontram seu espaço, defendendo o interesse geral; no segundo, não mais. Examinemos esse estudo de caso que mostra a implantação da política agroambiental.

\subsection{Resultados da observação}

Durante a primeira rodada, os debates em comitês técnicos se cristalizaram em torno da designação dos beneficiários e, mais especificamente, do lugar a ser reservado aos criadores (de gado) locais nos contratos. Há uma explicação estrutural para isso: a maioria dos prados úmidos é utilizada por agricultores que moram fora das áreas úmidas, no prado limítrofe. Desde a sistematização da drenagem com vistas a sistemas agropecuários mais intensivos, a criação em prados úmidos se tornou uma atividade duplamente desqualificada, por ser controlada por agricultores externos às áreas úmidas e por não ter rentabilidade econômica. Assim, a seleção dos beneficiários podia tomar dois rumos, que não são compatíveis e representam dois referenciais distintos para criar os contratos de gestão: ou partir de um conjunto de critérios ecológicos e se concentrar nas propriedades dos prados naturais úmidos, ou partir de uma leitura social da criação e fazer da situação do criador (morando ou não nas áreas úmidas) o critério de seleção do beneficiário. Em outras palavras, uma oposição entre duas formas de legitimidade (o que é justo selecionar): a excelência biológica contra o pertencimento territorial. A primeira foi defendida pelas associações de proteção ao meio ambiente; a segunda, 
pelos vereadores, que tentavam impor uma equivalência entre naturalidade e serviço prestado ao meio ambiente ${ }^{8}$.

Cinco anos mais tarde (cf. quadro abaixo), a segunda rodada oferece um quadro bem diferente, seja do ponto de vista das questões debatidas ou da representatividade. Essa mudança não se deve aos efeitos da política contratual aplicada até então: no caso estudado, 38\% dos agricultores que assinaram um contrato na primeira rodada moram nas áreas úmidas; cinco anos depois, eles são 35\%. Ou seja, a renovação ${ }^{9}$ corresponde até mesmo a uma leve diminuição da presença dos agricultores nas áreas úmidas na operação. No entanto, o exame comparativo do modo de construção do dispositivo agroambiental demonstra claramente que a questão da presença dos criadores nativos não ocupa mais os debates e que o problema maior é o da água e, através dele, a capacidade de um fórum de discussão para superar a oposição inicial entre excelência biológica e pertencimento social. O objetivo compartilhado é chegar a um acordo entre desenvolvimento social e reprodução do ecossistema de zona úmida. Um dos fatos marcantes que acompanham essa evolução é o desaparecimento dos vereadores nessa segunda rodada e o lugar assumido pelos próprios criadores, que representam às vezes mais da metade dos participantes das plenárias. A essa chegada, deve-se acrescentar a de novas "entidades naturais" (valas, abrigos para animais, plantas espinhosas, mosquitos, etc.) defendidas pelas associações de proteção da natureza. Mas essas associações não têm o monopólio, pois entram igualmente em cena novos atores (as agências da água, por exemplo), cuja convocação se impõe para bem considerar a materialidade da natureza na discussão. Em outras palavras, em torno da questão da representatividade, isto é, da composição da rodada, um cole-

\footnotetext{
${ }^{8}$ Eles defenderão, em particular, que a opinião dos prefeitos tenha o mesmo peso, em qualquer deliberação, que o parecer técnico, seja agronômico ou ecológico.

${ }^{9}$ Os contratos agroambientais são renovados a cada cinco anos.
} 
tivo técnico bem diferente se constitui aos poucos e, com ele, inicia-se a aprendizagem de outro tipo de gestão da zona úmida.

\subsection{Comparação das duas "rodadas" agroambientais com cinco anos de distância}

\begin{tabular}{|c|c|c|}
\hline & 1a rodada & $2^{\mathrm{a}}$ rodada \\
\hline Fase inicial & $\begin{array}{l}\text { Diagnóstico territorial global } \\
\text { (depois) Reivindicações profissionais }\end{array}$ & $\begin{array}{l}\text { Surgimento de uma questão: os meios } \\
\text { aquáticos e a gestão da água } \\
\text { (depois) Identificação dos problemas ex- } \\
\text { ternos à discussão agroambiental }\end{array}$ \\
\hline Enunciado & $\begin{array}{l}\text { Manutenção criador das áreas úmidas = } \\
\text { meio ambiente }\end{array}$ & $\begin{array}{l}\text { Manutenção do prado natural } \rightarrow \text { manu- } \\
\text { tenção do criador } \rightarrow \text { modos de gestão da } \\
\text { água }=\text { meio ambiente }\end{array}$ \\
\hline Problemas legítimos & $\begin{array}{l}\text { Quais criadores? } \\
\text { Opções que entram em conflito: } \\
\text { - sem seleção } \\
\text { - pertencimento local/profissional } \\
\text { - zoneamento ecológico (depois) } \\
\text { levantamento biológico }\end{array}$ & $\begin{array}{l}\text { Quais objetos? } \\
\text { - pasto parcial (cercas vivas e espinhos) } \\
\text { - cardo/mosquito/cágado-de-carapaça- } \\
\text { estriada } \\
\text { - caráter natural do prado } \\
\text { - poluições bacteriológicas } \\
\text { - qualidade das "baixas" } \\
\text { - juncais e aves } \\
\text { - abrigo para animais e rede }\end{array}$ \\
\hline $\begin{array}{l}\text { Debates técnicos em função da ele- } \\
\text { gibilidade das parcelas }\end{array}$ & $\begin{array}{l}\text { Quais práticas na parcela? } \\
\text { - data da colheita } \\
\text { - carga animal por hectare } \\
\text { - pasto invernal }\end{array}$ & $\begin{array}{l}\text { Quais práticas para a manutenção das } \\
\text { valas? } \\
\text { - estado inicial } \\
\text { - data, periodicidade e tipo de limpeza } \\
\text { - tratamento dos produtos de limpeza }\end{array}$ \\
\hline $\begin{array}{l}\text { Prioridade na alocação dos } \\
\text { recursos financeiros }\end{array}$ & Áreas úmidas e área externa a elas & $\begin{array}{l}\text { Prado natural (com modulação conforme } \\
\text { a \% de Prado natural/superfície) (depois) } \\
\text { prado temporário }\end{array}$ \\
\hline A semântica do contrato & "comprometimento fraco/forte" & "contrato biológico simples/reforçado" \\
\hline Os especialistas* & ADASEA, Câmara, INRA, LPO & $\begin{array}{l}\text { INRA, LPO, UNIMA, Agência da Água, } \\
\text { EID, Serviço de Proteção aos Vegetais } \\
\text { da DDA }\end{array}$ \\
\hline Atores dominantes & Vereadores (prefeitos) & Criadores e especialistas \\
\hline
\end{tabular}

" Associações francesas: ADASEA, Associações Departamentais para Ordenamento das Estruturas das Explorações Agrícolas; INRA, Instituto Nacional de Pesquisa Agronômica; LPO, Liga de Proteção aos Pássaros; UNIMA, União das Áreas Úmidas de Charente-Maritime; EID, União Interdepartamental para Desinsetização do Litoral Mediterrâneo; DDA, Associação dos Direitos dos Animais (N. de trad.). 


\subsection{Discussão}

A comparação entre essas duas rodadas agroambientais ilustra, do ponto de vista da gestão do território, o que o exercício dessa nova forma de democracia técnica pode envolver. Pode-se caracterizá-la a partir dos quatro traços seguintes:

- Uma justificativa que engloba uma pluralidade de saberes. É evidente que a posição dos defensores do ponto de vista "natural" (particularmente as associações de proteção da natureza) não é mais penalizada pela assimetria característica da primeira rodada: a legitimidade de sua participação em uma discussão, na época muito contestada pelos representantes da agricultura, é agora admitida. Essa mudança se deve à proximidade acarretada por todo processo dialógico: aprende-se a conhecer os outros e, sobretudo, a contornar as relações de poder. Mas ela se deve também à postura que as associações podem agora assumir, fazendo da criteriologia ecológica um verdadeiro objeto do debate social e se tornando legítimas portadoras de um conhecimento especializado. Essa criteriologia está de fato menos sujeita à incerteza de cinco anos antes: não é mais necessário esperar levantamentos biológicos, sempre demorados demais para o ritmo administrativo de montagem de um dossiê; quando se trata de enunciar precisamente um referencial técnico a partir da ecologia, as questões feitas por outros parceiros são respondidas. A tradução técnica do ponto de vista do ecólogo passa, por exemplo, pelo aporte de conhecimentos precisos sobre os períodos de nidificação, pela proposta de obras hidráulicas leves que permitam manter a água em certas pradarias, etc.

- Um enunciado sociotécnico. De certo modo, essa segunda fase das discussões agroambientais ilustra bem uma forma de recalcitrância da natureza (Latour, 1991): esta acabou por se impor na construção do 
dispositivo, por meio da mobilização de questões acerca dos níveis da água, da manutenção das valas e das obras hidráulicas. O novo enunciado que sanciona essa visão das áreas úmidas como um ecossistema emprega uma nova sintaxe - criador de áreas úmidas mais do que agricultor deste ou daquele território - e tenta elaborar prescrições que garantam as relações entre os criadores e o meio natural. É evidente que tal procedimento torna muito mais complexa a base do acordo: a equivalência entre o criador e a questão do meio ambiente não é postulada em opiniões, mas é testada em um sistema de inter-relações que, para ser validado, supõe a mobilização de elementos que digam respeito à prática agronômica, ao prado natural enquanto agrossistema e também à gestão da água. Trata-se, pois, de um enunciado sociotécnico, na medida em que tenta compatibilizar entidades naturais, técnicas disponíveis e indivíduos organizados.

- Um fórum de atores humanos e não humanos. Tudo isso só foi possível graças a uma modificação sensível do jogo de atores, pelo menos na distribuição dos papéis. O criador se impõe nas discussões técnicas (em detrimento do vereador, como já dissemos), mas também surgem novos parceiros. Apelando para seu know-how, a segunda rodada de discussões tenta incluir em seu coletivo problemas que, partindo de seu conhecimento prático, os criadores levantam, como a desinsetização de mosquitos (por um organismo semipúblico, o EID), ou o tratamento das plantas espinhosas (por um serviço especializado da direção Departamental da Agricultura). A mesma exigência de incluir o ser humano e o não humano no coletivo acarreta o surgimento de territorialidades particulares, aptas a se responsabilizar concretamente pelos problemas, como a gestão da água entre diferentes unidades administrativas (razão da inclusão dos Esquemas Departamentais de Ordenamento da Gestão da Água nas discussões) ou a poluição entre bacias hidrográficas (razão 
da presença das Agências da Água). Em outras palavras, a extensão do jogo de atores, com a consequente marginalização de certos parceiros da primeira fase (os vereadores), traduz uma grande ampliação da problemática, a inclusão de novas questões e, portanto, de novos objetos ${ }^{10}$. Nessa segunda rodada, a fronteira entre o que tange ao social e o que diz respeito ao natural é cada vez menos perceptível.

- Um acordo delimitado pela relação com os objetos (técnicos e naturais). O fato de focar na questão da água e, mais precisamente, na manutenção das valas ilustra bem um método que tende a incluir, por meio de correlações novas e complexas, o que diz respeito ao funcionamento do ecossistema e o que depende do funcionamento de um sistema de criação: juncais e aves; abrigos para animais e conexão com a vala, etc. A ênfase dada a essa inter-relação deslocou a discussão, que anteriormente incidia, sobretudo, sobre a parcela de áreas úmidas, para a vala que a cerca, o que indica mais abertura à complexidade. A vala é um lugar de circulação da água e, ao mesmo tempo, de práticas sociais de manutenção. Diferentemente da parcela em prado, que requer apenas uma prática privada e unívoca (a criação), a vala evoca várias práticas (a criação, mas também a caça e a pesca), assim como a interdependência própria à circulação da água em um sistema hidráulico onde se mesclam o individual e o coletivo, as atividades agrícola e malacologia, etc. Por essa razão, o acordo é a finalização de uma tentativa de tradução técnica e social dos diferentes pontos de vista. Sua manutenção envolve geralmente o contrato tradicional entre o criador, seu proprietário e o sindicato das áreas úmidas. Mas o contrato agroambiental incluirá uma cláusula consagrada à vala, pois criadores e associações de proteção ao meio ambiente a impõem aos representantes da administração que, querendo considerar apenas a parcela, não veem sua utilidade. Nenhum deles busca assim otimizar ganhos, mas valorizar uma interpreta- 
ção do contrato como novo pacto entre o criador e a área úmida. Em certo sentido, o valor dado à vala e à sua manutenção indica uma busca de equivalência, por parte dos atores envolvidos, nesta forma de democracia participativa que é a democracia técnica, entre as "necessidades da natureza" e as "necessidades dos indivíduos".

Desse modo, esses dispositivos que caracterizamos como "rodadas" (em sua capacidade de conciliar dados de natureza hibrida) constituem uma experiência coletiva para traduzir pontos de vista técnicos no desenvolvimento social. Ora, merece atenção o fato de que tal experiência tenha suposto que os vereadores, figuras emblemáticas da democracia representativa, se afastem em proveito dos criadores e dos especialistas, que constituíram de fato uma nova aliança no espaço público de discussão. Implicitamente, há sem dúvida conflito entre representações e competências e divergências quanto ao lugar de cada um na gestão do território e na justificativa do "bem comum". De um lado (a primeira rodada), traça-se de modo explícito uma fronteira entre a natureza e a sociedade e manifesta-se o desejo de separá-las, preservando assim o humano e o social (no caso, os criadores nativos) das restrições da natureza (em nome das quais o criador que não mora na área úmida poderia ser legítimo); do outro (a segunda rodada), tenta-se abolir ou pelo menos embaralhar a fronteira entre a natureza e a sociedade e chegar a um acordo baseado em uma hibridação das representações que, de fato, desqualifica o próprio fundamento da legitimidade rural, ou seja, o pertencimento a uma comunidade local. A primeira rodada se perde em discussões sobre desacordos de princípio, a segunda se abre para experimentar pontos de vista distintos, por meio de acordos limitados e práticas sobre incertezas compartilhadas.

O recuo do vereador, concomitante a essa transformação no processo dialógico, parece indicar que existe um hiato entre a representação instituída e aquela que se constrói nestes cenários mais experimentais, 
onde se ajustam questões técnicas e atores humanos e não humanos. Esse hiato merece nossa atenção, já que levanta a questão da articulação entre a democracia participativa e a democracia representativa.

\section{A ruralidade e o novo exercício democrático}

A ausência do ponto de vista do vereador na construção do dispositivo da segunda geração levanta uma questão mais geral, a da relação entre essa nova forma de democracia técnica que a consideração de problemas de meio ambiente em um âmbito participativo supõe e um modelo de gestão oriundo da história agrária das sociedades rurais, que privilegia o sentimento de pertencimento de seus participantes: haveria incompatibilidade ou, pelo menos, uma fonte de tensões entre duas formas de legitimidade? Essa questão está longe de ser nova no caso das áreas úmidas, cuja história inteira é produto da concorrência e do próprio conflito entre uma rede sociotécnica oriunda do ordenamento dos canais e o território das comunidades locais. De fato, essas áreas úmidas não foram trabalhados pelas comunidades locais, mas por atores (holandeses e burguesia urbana) que ignoravam deliberadamente seu território de pertencimento (Billaud, 1984). Essa particularidade não impede, a nosso ver, que se chegue a algumas conclusões mais gerais, pelo menos do ponto de vista das consequências da evolução das formas da ação pública nas sociedades rurais. A partir de nossa observação, salientaremos os seguintes pontos.

O traço mais marcante é, evidentemente, a mudança de contexto que, com os problemas de meio ambiente, mostra-se muito menos estável, pois marcado pela incerteza sobre os objetivos e, às vezes, até mesmo sobre os meios, assim como sobre a reação dos agentes humanos e não humanos. Em tal contexto, a discussão passa por cima do enquadramento regulamentar (foi o que aconteceu na politica agroambiental) para construir 
uma regra comum, do mesmo modo que o apelo aos conhecimentos, especialistas e leigos, sobrepuja o debate político para construir uma relação contratual capaz de delimitar a atividade dos diferentes agentes e assegurar que seu envolvimento não atenda só aos seus próprios interesses.

A legitimidade em um processo dialógico é constantemente posta em discussão porque o ajuste buscado só será possível se houver conjunção entre aqueles que dele participam e suas competências. É claro que o estabelecimento de tal conjunção passa por relações de força, pois a mobilização dos recursos que permitem debater não é a mesma entre os parceiros; no caso que apresentamos, as associações de proteção da natureza foram as mais afetadas nesse sentido.

Entretanto, esses dispositivos permanecem muito frágeis (ligados a um procedimento de política pública), assentados em uma territorialidade que pode ser efêmera (construída a partir da identificação de um problema ambiental: o caso de uma bacia hidrográfica, por exemplo): sua lógica é, então, acima de tudo instrumental e não se apresenta de início como resultado de um projeto coletivo que represente valores compartilhados. Ainda por cima, a exacerbação das questões de legitimidade não deve ocultar o desafio representado pela identificação de um princípio de responsabilidade aplicado ao controle da eficácia dessas novas formas contratuais, o que revela a real dificuldade dos dispositivos baseados na participação e na mobilização dos conhecimentos para ocupar o campo da arbitragem política.

O vereador, investido de uma função de representação de microssociedades, ficou desestabilizado, senão desqualificado, quando tentou insistir nessa arbitragem nos dispositivos agroambientais. Fazendo isso, ele lançou luz sobre uma tensão manifesta entre a democracia representativa e a democracia participativa. É evidente que a evocação do pertencimento territorial em detrimento da excelência biológica - neste caso, um princípio de gestão atinente a uma coletividade doméstica (Boltanski e Thévenot, 
1991) - estava fadada ao fracasso a partir do momento em que os atores envolvidos no espaço de discussão se dispuseram a cooperar para solucionar problemas práticos e técnicos. Apesar da incerteza que pode caracterizá-la, a mobilização de conhecimentos compartilhados se mostrou, desse ponto de vista, muito mais legítima na tentativa de fazer ajustes e chegar a acordos, mesmo temporários, e mais ainda quando tais acordos adquiriam sentido em uma escala diferente do espaço comunitário do vereador.

Isso significa que o vereador saiu definitivamente da cena local de gestão das situações de incerteza ou de risco, típicas das problemáticas ambientais? Vendo-se como mandatário dos interesses dos criadores de sua municipalidade, o vereador não avaliou a complexidade dessa nova forma de democracia técnica, que repousa em várias figuras: a dos que defendem interesses, mas também a dos que têm conhecimentos que, por seu confronto, compõem um coletivo inédito. O êxito da segunda rodada observada se deve ao fato de que os criadores, defensores de interesses, tornaram-se especialistas em suas próprias práticas e fizeram convergir as figuras da sociedade (os stakeholder) e da natureza (os conhecimentos), o que lhes deu legitimidade extra. Na primeira rodada, os vereadores misturaram essas duas figuras, privilegiando o interesse do criador não no terreno da especialização de sua prática, mas no da representação, desprovida de qualquer competência técnica. As novas situações de mobilização dos conhecimentos engendradas pela democracia técnica possibilitam, no entanto, o surgimento de papeis inéditos de "passadores" (Billaud, 2006) entre as fronteiras dos diferentes mundos presentes. Mais do que tentar figurar entre os defensores de interesses, assumindo a identidade do especialista ou o interesse geral, o vereador tem sem dúvida um papel a exercer nessas operações de tradução (Mormont, 2007), que não somente devem refletir o melhor acerto do ponto de vista dos ajustes entre conhecimentos práticos, mas também enunciar 
os princípios de justificativa e, portanto, de responsabilidade que guiam a ação pública no âmbito de todo o território.

Isso supõe, no entanto, que ele deixe para trás as justificativas próprias ao antigo sistema do pertencimento e enraizamento local e construa um novo discurso da "convivência" (Arendt, 1986), adaptado à problemática e às escalas próprias à gestão dos problemas de meio ambiente nos territórios rurais. A possibilidade de tornar mais compatíveis a democracia representativa e a democracia engendrada por essas arenas técnicas depende disso e, com ela, os modos de legitimação da ação pública e coletiva nas sociedades rurais.

Nas sociedades rurais tradicionais, o espaço agrícola era, de fato, um espaço técnico totalmente socializado devido ao pertencimento dos grupos sociais a uma "comunidade" local. A transformação radical desse espaço em razão da "modernização" e da intensificação da produção, acompanhadas do êxodo rural, incidiu tanto sobre sua morfologia física quanto sobre sua organização social: o surgimento atual dessas arenas de debates sociotécnicos, baseados na participação dos cidadãos, é um sintoma dessa transformação, mas os arranjos a que eles chegam não são mais um elemento necessariamente fundador de um laço social dos grupos de pertencimento, como os que prevalecem nas sociedades rurais. $\mathrm{O}$ aparecimento desses espaços de debate que delineiam novos coletivos levanta a questão da interação tradicional, expressa na ordem democrática pela democracia representativa.

O vínculo entre essas interações funcionais, particularmente institucionalizadas pelos dispositivos que tratam de problemas ambientais, e o que constitui uma aspiração à convivência (Dodier, 1997) não é evidente: que lugar atribuir a essas arenas sociotécnicas no que a sociologia rural qualificava de sociedades ou coletividades rurais? Nesse caso, lidamos com duas tipologias diferentes: a territorialidade construída para solucionar um problema ambiental não é aquela produzida pelos mul- 
tipertencimentos dos indivíduos, que têm apesar de tudo como quadro territorial de referência o espaço da coletividade local. Os agricultores, por exemplo, não podem mais tratar a questão de sua relação com a natureza de modo implícito: identificando-a como um problema específico, eles são não somente levados a se interrogar sobre suas próprias práticas, mas também a construir com os outros atores do espaço rural, que também são usuários, um novo modo de "convivência". Deve-se então não somente estudar as interações produzidas nesses espaços dialógicos, mas também analisar os modos de articulação entre os diferentes lugares que "fazem sociedade", aqueles abarcados tradicionalmente pela democracia representativa, mas também os que, cada vez mais, dizem respeito a uma democracia participativa. Essa articulação não está dada e deve ser construída pelos diferentes coletivos que as diversas formas do exercício democrático criam atualmente.

Jean-Paul Billaud é diretor de pesquisa do Centro Nacional de Pesquisa Científica (CNRS), França, junto ao Laboratório Dinâmicas Sociais e Recomposição dos Espaços (LADYSS), especializado em Sociologia Rural e Sociologia do Meio Ambiente e coeditor da revista Nature Sciences Sociétés. $\longrightarrow$ billaud@u-paris10.fr

\section{Referências}

1. ARENDT, H. Vies politiques. Paris: Gallimard, 1986.

2. BILLAUD, J.-P. Marais Poitevin. Rencontres de la terre et de l'eau. Paris: I'Harmattan, 1984. 266 p.

3. BILLAUD, J.-P., Les analyses de la cogestion en France. In: COULOMB, P.; DELORME, H.; HERVIEU, B.; JOLLIVET, M.; LACOMBE, P. (Eds.). Les agriculteurs et la politique. Paris: Presses de Sciences Po, 1990. p. 226-236

4. BILLAUD, J.-P. (Ed.). Environnement et gestion des territoires. L'expérience agrienvironnementale française. Paris: La documentation française, 2002. 372 p.

5. BILLAUD, J.-P. Ce que faciliter veut dire. A propos d'un retour d'expérience de chargés de mission Natura 2000. In: Conseiller en agriculture. RÉMY, J.; BRIVES, H; LEMERY, B. (Eds.). Educagri éd./Inra éd., 2006. 276 p. 
6. BLONDIAUX, L.; Fourniau, J.-M.; Un bilan des recherches sur la participation du, public en démocratie : beaucoup de bruit pour rien?, Participations (1), p. 8-35, 2011.

7. BOLTANSKI, L.; THEVENOT, L. De la justification. Les économies de la grandeur. Paris: Gallimard, 1991.

8. CALLON, M. Des différentes formes de démocratie technique. Annales des Mines, p. 63-73, 1998.

9. CALLON, M.; LASCOUMES, P.; BARTHE, Y. Agir dans un monde incertain: Essai sur la démocratie technique. Paris: Seuil, 2001.

10. COULOMB, P.; NALLET, H. Les organisations syndicales agricoles à l'épreuve de l'unité, In: TAVERNIER, Y.; GERVAIS, M.; SERVOLIN, C. L'univers politique des paysans. Paris: Presses de Sciences Po, 1972. p. 379-414.

11. CROZIER, M.; THOENIG, J.-C. La régulation des systèmes organisés complexes. Le cas du système de décision politico-administratif local en France, Revue française de sociologie, 16 (1), janvier-mars, 1976.

12. DEWEY, J. Le public et ses problèmes. Paris: Gallimard: "Folio Essais", 2010. $336 \mathrm{p}$.

13. DODIER, N. Leçons politiques de I'épidémie du sida. Paris: Edition de I'Ecole des Hautes Etudes en Sciences sociales, 2003. 360 p.

14. DODIER, N. Remarques sur la conscience du collectif dans les réseaux sociotechniques, Sociologie du Travail, 2 : 131-148, 1997.

15. DURAN, P.; THOENIG, J.-C. L'Etat et la gestion publique territoriale, Revue Française de Science Politique, n² , vol. 46, 1996.

16. HABERMAS, J. Théorie de I'agir communicationnel. 2 tomes, Paris: Fayard, 1987.

17. LATOUR, B. Nous n'avons jamais été modernes. Essai d'anthropologie symétrique. Paris: La Découverte, 1991.

18. LATOUR, B.; WOOLGAR, S. La vie de laboratoire. La production des faits scientifiques. Paris: La Découverte, 1996.

19. LAURENT, C. Evidence-based-policy. La qualité des preuves, Le Courrier de la Planète, n 93, 2011.

20. MILLON-DELSOL, C. Le Principe de Subsidiarité. Paris: PUF, 1993.

21. MORMONT, M. Agriculture et environnement: pour une sociologie des dispositifs, Economie Rurale, 236 : 28-36, 1996. 
22. MORMONT, M. Des savoirs actionnables. In: AMOUKOU, I.; WAUTELET, J.-M. Croisement des savoirs villageois et universitaires. Louvain La Neuve, Presses Universitaires de Louvain, 2007.

23. PESTRE, D. Des sciences, des techniques et de l'ordre démocratique et participatif, Participations (1), 210-238, 2011.

24. ROSANVALLON, P. Écrire une histoire générale de la démocratie, Participations (1), 335-347, 2011.

25. SINTOMER, Y. Délibération et participation : affinité élective ou concepts en tension?, Participations (1), 239-276, 2011.

26. SUTHERLAND, W.; PULLIN, A.; DOLMAN, P.; KNIGHT, T. The need for evidence-based conservation, Trends in Ecology and Evaluation, vol. 19, $\mathrm{n}^{\circ} 6$, 305-308, 2004.

27. THOENIG, J.-C. L'ère des technocrates. Paris: L'Harmattan, 1987.

28. WALZER, M. Spheres of justice. A defense of pluralism and equity. NewYork: Basic Books, 1983.

Recebido em: 05/08/2013

Aceite final: 02/12/2013 